\title{
Implication of polymorphisms in DNA repair genes with an increased risk of hepatocellular carcinoma
}

J.S. Wu ${ }^{1}$, Y.P. Chen ${ }^{2}$, L.C. Wang ${ }^{3}$, Y.J. Yang ${ }^{4}$, C.W. Deng ${ }^{1}$, B.X. Hou ${ }^{3}$, Z.L. He ${ }^{5}$ and J.X. Chen ${ }^{5}$

${ }^{1}$ Oncology Department, Hainan Province Nongken Nada Hospital, Danzhou, China

${ }^{2}$ Department of Digestive System, Hainan Province Nongken Nada Hospital, Danzhou, China

${ }^{3}$ Department of General Surgery, Hainan Province Nongken Sanya Hospital, Danzhou, China

${ }^{4}$ Department of Digestive System, Hainan Province Nongken Sanya Hospital, Danzhou, China

${ }^{5}$ Department of General Surgery, Ninth People's Hospital, Chongqing, China

Corresponding author: B.X. Hou

E-mail: houbenxin2010@sina.com

Genet. Mol. Res. 13 (2): 3812-3818 (2014)

Received July 8, 2013

Accepted December 5, 2013

Published May 16, 2014

DOI http://dx.doi.org/10.4238/2014.May.16.5

ABSTRACT. We explored the association between 4 XRCC1 (Arg194Trp and Arg399Gln) and XPD (Asp312Asn and Lys751Gln) polymorphisms with the development and prognosis of hepatocellular carcinoma (HCC). A total of 218 cases with HCC and 277 healthy controls were included in the study. Genotyping of the XRCC1 (Arg194Trp and Arg399Gln) and XPD (Asp312Asn and Lys751Gln) polymorphisms was performed in a 384-well plate format on the Sequenom MassARRAY platform. We found that individuals with the XRCC1 399AA genotype had a higher risk of HCC compared with the GG genotype (odds ratio, $\mathrm{OR}=1.85,95 \%$ confidence interval, $\mathrm{CI}=$ 
1.03-3.23). Similarly, individuals carrying the $X P D 751 \mathrm{GG}$ genotype showed a greatly increased risk of $\mathrm{HCC}(\mathrm{OR}=2.97,95 \% \mathrm{CI}=126-$ 7.38). Cox regression analysis showed that individuals carrying $X P D$ $751 \mathrm{Gln} / \mathrm{Gln}$ genotypes had a 0.30 -fold increased risk of death from HCC. These results suggest that polymorphisms in XRCC1 and XPD may have functional significance in HCC.

Key words: XRCC1; XPD; Polymorphism; Hepatocellular carcinoma; Susceptibility; Clinical outcome

\section{INTRODUCTION}

Hepatocellular carcinoma (HCC) is the fifth most common cancer among both men and women worldwide, and it is a major burden in developing countries. The wide geographic variation of $\mathrm{HCC}$ indicates the role of genetic and environmental factors in the development of HCC [International Agency for Research on Cancer (IARC), 2012]. The primary etiological factor for HCC is chronic hepatitis B virus (HBV) infection; however, less than $10 \%$ of HBVand hepatitis C (HCV)-infected individuals developed HCC during their lifetime (Lavanchy, 2004; Bowen and Walker, 2005). HCC typically develops in a background of cirrhosis from various etiologies, but mostly following HCV or HBV infection or excessive alcohol intake (Yu and Yuan, 2004; Davila et al., 2004). Therefore, other factors, such as environmental compounds and genetic polymorphisms, may impact HCC development.

Various DNA repair systems are involved in base excision (BER), nucleotide excision repair (NER), mismatch repair (MMR), and double-strand break repair (DSBR), among others. NER is the main DNA repair system, and constitutes the main defense against lesions generated by ionizing radiation and strong alkylating agents as well as lesions formed by endogenous DNA-damaging agents such as viruses (Smith et al., 2003). NER is reportedly to be associated with the development of various cancers (Han et al., 2012; Mandal et al., 2012).

The $X R C C 1$ and $X P D$ genes are 2 major repair genes in the NER system, and their polymorphisms are associated with changes in the repair efficiency of DNA damage, as well as the risk of cancer, birth defects, and a reduced life span (Ronen and Glickman, 2001). XRCC1 and XPD have been reported to be associated with a risk of various cancers. However, few studies have examined the association between these gene polymorphisms and HCC. Therefore, we explored the association between 4 XRCC1 (Arg194Trp and Arg399Gln) and XPD (Asp312Asn and Lys751Gln) polymorphisms and the development and prognosis of HCC.

\section{MATERIAL AND METHODS}

\section{Subjects}

Patients with HCC were recruited consecutively from the Ninth People's Hospital and Jiangjin Central Hospital in China from May 2006 to October 2008. A total of 218 cases with HCC were histologically confirmed at the Ninth People's Hospital and Jiangjin Central Hospital. All patients were HBV surface antigen (HBsAg) carriers with $\mathrm{HCC}$, and the diagnosis of HCC was made by liver biopsy or a combination of increased alpha-fetoprotein ( $\geq 200 \mathrm{ng} / \mathrm{mL}$ ) 
and the typical vascular pattern on angiography or dynamic imaging. Clinical information, such as tumor differentiation, tumor size, Child-Pugh score, and surgery types, were collected from medical records with the patients' consent. All patients were followed-up until the end of April 2012. Tumor progression was defined as postoperative tumor recurrence and distant metastasis. The overall survival time was defined as the date of tumor resection or the first local treatment until the date of death.

A total of 277 controls were recruited from participants in the health examination center from May 2006 to October 2008, and were matched with the cases by age ( \pm 5 years). Control subjects with a history of cancer and digestive system disease were excluded. The ethical committee of the Ninth People's Hospital and Jiangjin Central Hospital approved the study and consent was obtained from all participants.

\section{DNA collection, gene selection, and genotyping}

A 5-mL blood sample was collected from each subject. DNA was extracted from frozen white blood cells using the buffy-coat fractions with the TIANamp blood DNA kit (Tiangen Biotech; Beijing, China). Genotyping of XRCC1 (Arg194Trp and Arg399Gln) and $X P D$ (Asp312Asn and Lys751Gln) was performed in a 384-well plate format on the Sequenom MassARRAY platform (Sequenom; San Diego, CA, USA). Primers for polymerase chain reaction (PCR) amplification and single base extension (SBE) assays were designed using the Sequenom Assay Design 3.1 software (Sequenom) according to manufacturer instructions. PCR conditions were as follows: $94^{\circ} \mathrm{C}$ for $4 \mathrm{~min}$, followed by 35 cycles of $94^{\circ} \mathrm{C}$ for $30 \mathrm{~s}, 61^{\circ} \mathrm{C}$ for $30 \mathrm{~s}$, and $72^{\circ} \mathrm{C}$ for $30 \mathrm{~s}$, and a final elongation step at $72^{\circ} \mathrm{C}$ for $7 \mathrm{~min}$. For quality control, we performed genotyping of a $10 \%$ random sample of cases and controls twice by different researchers. Quality control analysis confirmed 100\% concordance.

\section{Statistical analysis}

The Stata 10.0 software (StataCorp; College Station, TX, USA) was used for statistical analyses. Single nucleotide polymorphism (SNP) genotypes were tested for Hardy-Weinberg equilibrium (HWE) among controls. Means \pm standard deviation (SD) was used for continuous variables, and frequencies and percentages were used for categorical variables. The chi-square test or Student's $t$-test were used to compare demographic characteristics between cases and controls. The association between the 4 SNPs and risk of HCC was estimated by computing the odd ratios (ORs) and their $95 \%$ confidence intervals ( $95 \% \mathrm{CIs}$ ) from conditional logistic regression models. The homozygous genotypes for these SNPs were used as references. P values were considered to be statistically significant when less than or equal to 0.05 .

\section{RESULTS}

\section{General characteristics of the subjects}

A total of 218 HCC subjects and 277 healthy controls were enrolled in our study. The general characteristics of all subjects are summarized in Table 1. As expected, no significant difference was found between cases and controls in terms of gender and age $(P>0.05)$. We found 
that HCC patients were more likely to consume alcohol and have a family history of cancer, HBV, and $\mathrm{HCV}$ infection. Of the 218 patients, $67.8 \%$ were at Tumor-Necrosis-Metastasis (TNM) stage III-IV, $65.2 \%$ presented liver cirrhosis, and approximately $75 \%$ showed Child-Pugh B and C stages.

\begin{tabular}{|c|c|c|c|c|c|}
\hline \multirow[t]{2}{*}{ Characteristics } & \multirow{2}{*}{$\begin{array}{c}\text { Case } \\
\mathrm{N}=218\end{array}$} & \multirow[t]{2}{*}{$\%$} & \multirow{2}{*}{$\begin{array}{c}\text { Control } \\
\mathrm{N}=277\end{array}$} & \multirow[t]{2}{*}{$\%$} & \multirow[t]{2}{*}{$P$ value } \\
\hline & & & & & \\
\hline Age (means \pm SD), years & $52.2 \pm 8.5$ & & $53.7 \pm 10.2$ & & 0.95 \\
\hline \multicolumn{6}{|l|}{ Gender } \\
\hline Male & 143 & 65.6 & 159 & 57.4 & \multirow[t]{2}{*}{0.06} \\
\hline Female & 75 & 34.4 & 118 & 42.6 & \\
\hline \multicolumn{6}{|l|}{ Smoking status, $\%$} \\
\hline Smokers & 76 & 34.9 & 77 & 27.8 & \multirow[t]{2}{*}{0.09} \\
\hline Non-smokers & 142 & 65.1 & 200 & 72.2 & \\
\hline \multicolumn{6}{|l|}{ Drinking status, \% } \\
\hline Drinkers & 101 & 46.3 & 102 & 36.8 & \multirow[t]{2}{*}{0.03} \\
\hline Non-drinkers & 117 & 53.7 & 175 & 63.2 & \\
\hline \multicolumn{6}{|l|}{ Family history of cancer, $\%$} \\
\hline Yes & 17 & 7.8 & 2 & 0.7 & \multirow[t]{2}{*}{$<0.001$} \\
\hline No & 201 & 92.2 & 275 & 99.3 & \\
\hline \multicolumn{6}{|l|}{ HBV } \\
\hline+ & 114 & 52.3 & 20 & 7.2 & \multirow[t]{2}{*}{$<0.001$} \\
\hline - & 104 & 47.7 & 257 & 92.8 & \\
\hline \multicolumn{6}{|l|}{$\mathrm{HCV}$} \\
\hline+ & 16 & 7.4 & 3 & 1.1 & \multirow[t]{2}{*}{$<0.001$} \\
\hline - & 202 & 92.6 & 274 & 98.9 & \\
\hline \multicolumn{6}{|l|}{ TNM stage } \\
\hline I-II & 70 & 32.2 & & & \\
\hline III-IV & 148 & 67.8 & & & \\
\hline \multicolumn{6}{|l|}{ Liver cirrhosis } \\
\hline Present & 142 & 65.2 & & & \\
\hline & 76 & 34.8 & & & \\
\hline \multicolumn{6}{|l|}{ Child-Pugh classification } \\
\hline A & 52 & 23.8 & & & \\
\hline B & 86 & 39.5 & & & \\
\hline $\mathrm{C}$ & 80 & 36.7 & & & \\
\hline
\end{tabular}

\section{Genotype frequency and effect on HCC development}

Genotype frequency distributions of XRCC1 Arg194Trp, XRCC1 Arg399Gln, XPD Lys $751 \mathrm{Gln}$, and XPD Asp312Asn polymorphisms are shown in Table 2. The genotypic frequencies of the controls were in HWE. We found a significant difference between cases and controls in the proportion of XRCC1 Arg194Trp and XPD Asp312Asn polymorphisms. However, we found that individuals with the XRCC1 399AA genotype had a higher risk of HCC compared with the GG genotype $(\mathrm{OR}=1.85,95 \% \mathrm{CI}=1.03-3.23)$. Similarly, individuals carrying the $X P D 751 \mathrm{GG}$ genotype showed a large increased risk of $\mathrm{HCC}(\mathrm{OR}=2.97,95 \% \mathrm{CI}=1.26-7.38)$.

\section{Genotype effects on overall survival of HCC}

There were 94 deaths among the 218 cases. The median survival time of included cases was 31 months. A multivariate analysis of genotype effects on survival based on Cox proportional hazards models is shown in Table 3. The XRCC1 Arg399Gln and XPD Lys751Gln poly- 
morphisms were observed to be significant independent predictors of overall survival among all patients. The XPD 751GG genotype was observed to increase the survival of HCC patients when compared with the XPDCC genotype [hazard ratio $(\mathrm{HR})=0.30,95 \% \mathrm{CI}=0.06-0.94$ ].

\begin{tabular}{|c|c|c|c|c|c|c|}
\hline \multirow[t]{2}{*}{ Single nucleotide polymorphism } & \multirow{2}{*}{$\begin{array}{c}\text { Cases } \\
\mathrm{N}=218\end{array}$} & \multirow[t]{2}{*}{$\%$} & \multirow{2}{*}{$\begin{array}{l}\text { Controls } \\
\mathrm{N}=277\end{array}$} & \multirow[t]{2}{*}{$\%$} & \multirow[t]{2}{*}{$P$ value } & \multirow[t]{2}{*}{ OR $(95 \% \mathrm{CI})$} \\
\hline & & & & & & \\
\hline \multicolumn{7}{|l|}{ XRCC1 Arg194Trp (rs1799782) } \\
\hline $\mathrm{CC}$ & 151 & 69.3 & 198 & 71.5 & - & 1.0 (Ref.) \\
\hline $\mathrm{CT}$ & 55 & 25.2 & 68 & 24.5 & 0.78 & $1.06(0.68-1.64)$ \\
\hline TT & 12 & 5.5 & 11 & 4 & 0.40 & $1.43(0.56-3.68)$ \\
\hline \multicolumn{7}{|l|}{ XRCC1 Arg399Gln (rs25487) } \\
\hline GG & 108 & 49.5 & 161 & 58.1 & - & 1.0 (Ref.) \\
\hline GA & 74 & 33.9 & 87 & 31.4 & 0.24 & $1.27(0.84-1.92)$ \\
\hline AA & 36 & 16.6 & 29 & 10.5 & 0.02 & $1.85(1.03-3.23)$ \\
\hline \multicolumn{7}{|l|}{ XPD Lys751Gln (rs13181) } \\
\hline $\mathrm{CC}$ & 105 & 48.2 & 156 & 56.3 & - & 1.0 (Ref.) \\
\hline CG & 93 & 42.7 & 111 & 40.1 & 0.24 & $1.24(0.84-1.83)$ \\
\hline & 20 & 9.1 & 10 & 3.6 & 0.005 & $2.97(1.26-7.38)$ \\
\hline \multicolumn{7}{|l|}{ XPD Asp312Asn (rs1799793) } \\
\hline $\mathrm{CC}$ & 138 & 63.3 & 181 & 65.3 & - & 1.0 (Ref.) \\
\hline СT & 58 & 26.6 & 70 & 25.3 & 0.69 & $1.09(0.70-1.68)$ \\
\hline TT & 22 & 10.1 & 26 & 9.4 & 0.74 & $1.11(0.57-2.13)$ \\
\hline
\end{tabular}

Table 3. The survival of hepatocellular carcinoma by polymorphisms in XRCC1 and XPD genes.

\begin{tabular}{|c|c|c|c|c|c|c|}
\hline \multirow[t]{2}{*}{ Genotype } & \multirow{2}{*}{$\begin{array}{c}\text { Case } \\
\mathrm{N}=218\end{array}$} & \multirow[t]{2}{*}{$\%$} & \multirow{2}{*}{$\begin{array}{c}\text { Death } \\
\mathrm{N}=94\end{array}$} & \multirow[t]{2}{*}{$\%$} & \multirow[t]{2}{*}{$P$ value } & \multirow[t]{2}{*}{$\mathrm{HR}(95 \% \mathrm{CI})^{1}$} \\
\hline & & & & & & \\
\hline \multicolumn{7}{|c|}{ XRCC1 Arg194Trp (rs1799782) } \\
\hline $\mathrm{CC}$ & 151 & 69.3 & 68 & 72.6 & - & 1.0 (Ref.) \\
\hline $\mathrm{CT}$ & 55 & 25.2 & 23 & 24.1 & 0.67 & $0.93(0.51-1.68)$ \\
\hline TT & 12 & 5.5 & 3 & 3.3 & 0.2 & $0.55(0.10-2.15)$ \\
\hline \multicolumn{7}{|c|}{ XRCC1 Arg399Gln (rs25487) } \\
\hline GG & 108 & 49.5 & 54 & 57.4 & - & 1.0 (Ref.) \\
\hline GA & 74 & 33.9 & 31 & 32.5 & 0.34 & $0.83(0.47-1.47)$ \\
\hline AA & 36 & 16.6 & 9 & 10.1 & 0.02 & $0.5(0.20-1.16)$ \\
\hline \multicolumn{7}{|c|}{ XPD Lys751Gln (rs13181) } \\
\hline $\mathrm{CC}$ & 105 & 48.2 & 52 & 55.6 & - & 1.0 (Ref.) \\
\hline CG & 93 & 42.7 & 39 & 41.3 & 0.34 & $0.84(0.50-1.44)$ \\
\hline GG & 20 & 9.1 & 3 & 3.1 & 0.003 & $0.30(0.06-0.94)$ \\
\hline \multicolumn{7}{|c|}{ XPD Asp312Asn (rs1799793) } \\
\hline $\mathrm{CC}$ & 138 & 63.3 & 61 & 65.1 & - & 1.0 (Ref.) \\
\hline $\mathrm{CT}$ & 58 & 26.6 & 24 & 25.7 & 0.74 & $0.93(0.51-1.70)$ \\
\hline TT & 22 & 10.1 & 9 & 9.2 & 0.64 & $0.93(0.35-2.24)$ \\
\hline
\end{tabular}

\section{DISCUSSION}

We investigated the role of $X R C C 1$ and $X P D$ gene polymorphisms on the susceptibility and prognosis of HCC. Our study indicated that XRCC1 Arg399Gln and XPD 751Gln/Gln were associated with the development of HCC. Previous studies suggested that XRCC1 Arg399Gln and $X P D 751 \mathrm{Gln} / \mathrm{Gln}$ were associated with the risk of early-onset HCC (Kiran et al., 2009; Long et al., 2009). In this study, XRCC1 Arg399Gln and XPD Asp312Asn were associated with increased risk of HCC. Moreover, the XPD Asp312Asn polymorphism was significantly 
associated with increased overall survival according to multivariate Cox regression analysis, suggesting that the 2 genes are associated with a favorable prognosis in patients with HCC.

Various types of DNA damage may occur during endogenous metabolic processes or by environmental carcinogens. If such DNA damage is not repaired, genetic instability, mutagenesis, cell death, and reduced genome integrity, as well as carcinogenesis can occur. NER is the main DNA damage repair pathway for small base lesions from oxidation and alkylation damage. The XRCC1 and XPD proteins are important in the multistep NER pathway, and consist of 3 functional domains that interact with different enzymes to initiate the DNA repair of different stages and types (Ramachandran et al., 2006). The polymorphisms in the $X R C C 1$ and $X P D$ genes are associated with cancer development in patients with varying levels of radiosensitivity. HBV and $\mathrm{HCV}$ were found to be risk factors of $\mathrm{HCC}$, and these 2 factors may cause chromosomal instability or insertional mutations, thus inducing the risk of carcinoma development. XRCC1 Arg399Gln and XPD Asp312Asn altered the function of the XRCC1 and XPD proteins, and in turn altered cancer susceptibility (Zhang et al., 2012b; Cui et al., 2012). A previous study conducted in China indicated that the XRCC1 Arg399Gln polymorphism was associated with a significantly increased risk of HCC under the conditions of HBV infection (Long et al., 2008). Another study with $618 \mathrm{HCC}$ cases and 712 controls indicated that the XPD Lys751Gln polymorphism is an important modulator of AFB1-related HCC development in the Guangxi population (Long et al., 2009). Our study showed that the XRCC1 Arg399Gln and XPD Lys751Gln polymorphisms may increase the risk of $\mathrm{HCC}$, which agrees with the results of previous studies.

Radiotherapy and chemotherapy for HCC induces DNA damage of cancer cells, and the low activity of the XPD Lys 751 Gln polymorphism strengthens the efficacy of therapy. The role of the XPD Lys $751 \mathrm{Gln}$ polymorphism is reportedly associated with increased function of chemotherapy for various cancers, such as colorectal cancer, esophageal cancer, and non-small cell lung cancer (Gan et al., 2012; Zhang et al., 2012a; Li and Sun, 2013). Our study agreed with the results of previous studies, which provides solid evidence for the above hypothesis. We observed that the $X P D 751 \mathrm{Gln} / \mathrm{Gln}$ polymorphism played a significant prognostic role in the survival of HCC patients in the Chinese population. Moreover, genetic information regarding the polymorphisms and gene expression patterns may play an important role in developing successful pharmacogenetic-guided chemotherapy.

In conclusion, our data suggest that polymorphisms in XRCC1 Arg399Gln and XPD Lys $751 \mathrm{Gln}$ are related to $\mathrm{HCC}$ risk in the Chinese population. Moreover, the genotype of XPD $751 \mathrm{Gln} / \mathrm{Gln}$ was associated with a reduction in the death rate from HCC. Our findings were based on a relatively small number of patients. Larger sample studies from the Chinese population should be examined.

\section{REFERENCES}

Bowen DG and Walker CM (2005). Adaptive immune responses in acute and chronic hepatitis C virus infection. Nature 436: 946-952.

Cui Z, Yin Z, Li X, Wu W, et al. (2012). Association between polymorphisms in XRCC1 gene and clinical outcomes of patients with lung cancer: a meta-analysis. BMC Cancer 12: 71.

Davila JA, Morgan RO, Shaib Y, McGlynn KA, et al. (2004). Hepatitis C infection and the increasing incidence of hepatocellular carcinoma: a population-based study. Gastroenterology 127: 1372-1380.

Gan Y, Li XR, Chen DJ and Wu JH (2012). Association between polymorphisms of XRCC1 Arg399Gln and XPD Lys751Gln genes and prognosis of colorectal cancer in a Chinese population. Asian Pac. J. Cancer Prev. 13: 57215724. 
Han W, Kim KY, Yang SJ, Noh DY, et al. (2012). SNP-SNP interactions between DNA repair genes were associated with breast cancer risk in a Korean population. Cancer 118: 594-602.

International Agency for Research on Cancer (IARC) (2012). Liver Cancer Incidence and Mortality Worldwide in 2011. Available at [http://globocan.iarc.fr/factsheets/cancers/liver.asp]. Accessed October 20, 2013.

Kiran M, Saxena R, Chawla YK and Kaur J (2009). Polymorphism of DNA repair gene XRCC1 and hepatitis-related hepatocellular carcinoma risk in Indian population. Mol. Cell Biochem. 327: 7-13.

Lavanchy D (2004). Hepatitis B virus epidemiology, disease burden, treatment, and current and emerging prevention and control measures. J. Viral Hepat. 11: 97-107.

Li RZ and Sun J (2013). Association between XPD gene polymorphisms and esophageal squamous cell carcinoma. Mol. Med. Rep. 7: 674-678.

Long XD, Ma Y, Huang HD, Yao JG, et al. (2008). Polymorphism of XRCC1 and the frequency of mutation in codon 249 of the p53 gene in hepatocellular carcinoma among Guangxi population, China. Mol. Carcinog. 47: 295-300.

Long XD, Ma Y, Zhou YF, Yao JG, et al. (2009). XPD codon 312 and 751 polymorphisms, and AFB1 exposure, and hepatocellular carcinoma risk. BMC Cancer 9: 400.

Mandal RK, Gangwar R, Kapoor R and Mittal RD (2012). Polymorphisms in base-excision \& nucleotide-excision repair genes \& prostate cancer risk in north Indian population. Indian J. Med Res. 135: 64-71.

Ramachandran S, Ramadas K, Hariharan R, Rejnish KR, et al. (2006). Single nucleotide polymorphisms of DNA repair genes XRCC1 and XPD and its molecular mapping in Indian oral cancer. Oral Oncol. 42: 350-362.

Ronen A and Glickman BW (2001). Human DNA repair genes. Environ. Mol. Mutagen. 37: 241-283.

Smith TR, Miller MS, Lohman K, Lange EM, et al. (2003). Polymorphisms of XRCC1 and XRCC3 genes and susceptibility to breast cancer. Cancer Lett. 190: 183-190.

Yu MC and Yuan JM (2004). Environmental factors and risk for hepatocellular carcinoma. Gastroenterology 127: S72-S78.

Zhang L, Ruan Z, Hong Q, Gong X, et al. (2012a). Single nucleotide polymorphisms in DNA repair genes and risk of cervical cancer: A case-control study. Oncol. Lett. 3: 351-362.

Zhang ZY, Tian X, Wu R, Liang Y, et al. (2012b). Predictive role of ERCC1 and XPD genetic polymorphisms in survival of Chinese non-small cell lung cancer patients receiving chemotherapy. Asian Pac. J. Cancer Prev. 13: 2583-2586. 